\title{
Reversible transformation of a supramolecular hydrogel by redox switching of methylene blue - a non-covalent chain stopper
}

Suneesh C. Karunakaran*, Brian J. Cafferty, Kyan S. Jain, Gary B. Schuster and Nicholas V. Hud

School of Chemistry and Biochemistry, Georgia Institute of Technology, Atlanta, Georgia, 30332

Table of contents

\begin{tabular}{|c|l|c|}
\hline \multicolumn{2}{|l|}{ Supplementary Figures } & Page No. \\
\hline S1 & $\begin{array}{l}\text { Determination of minimum assembly concentration (MAC) } \\
\text { of TAP-CyCo6 assembly without and with MB }\end{array}$ & 2 \\
\hline S2 & $\begin{array}{l}\text { Absorption spectra of MB in methanol and in phosphate } \\
\text { buffer }\end{array}$ & 3 \\
\hline S3 & $\begin{array}{l}\text { Changes in pH of the solutions of MB in buffer or in TAP- } \\
\text { CyCo6 assemblies with added ascorbic acid }\end{array}$ & 3 \\
\hline S4 & $\begin{array}{l}\text { Kinetics of ascorbic acid mediated decolouration of MB in } \\
\text { buffer and in TAP-CyCo6 assembly }\end{array}$ & 4 \\
\hline
\end{tabular}




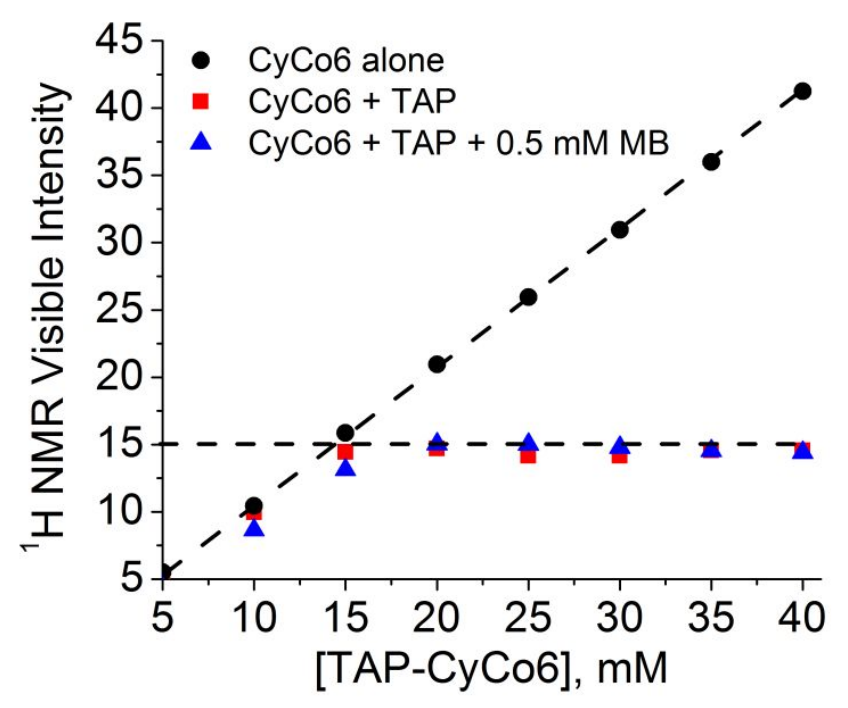

Figure S1. Determination of minimum assembly concentration (MAC) of TAPCyCo6 assemblies in the absence and presence of MB. The solution phase concentration of CyCo6 as determined by integration of the observed methylene ${ }^{1} \mathrm{H}$ NMR signals versus actual CyCo6 concentration in 1:1 mixture with TAP in the absence and presence of $0.5 \mathrm{mM} \mathrm{MB}$. CyCo6 without TAP is also shown to illustrate the linear response obtained when polymers are not present. The plateau of signal intensity for samples containing TAP and CyCo6 indicate the minimum assembly concentration (MAC) of $15 \mathrm{mM}$. The MAC of the system is found to unchanged with the addition of MB as a chain stopper. This experiment reveals that $15 \mathrm{mM}$ of both TAP and CyCo6 are free in solution for samples containing $30 \mathrm{mM}$ TAP and CyCo6, without or with MB as chain stopper, and which means that MB shorten the length of the TAP-CyCo6 supramolecular polymers, but they do not alter the total number of assembled TAP and CyCo6 monomers in solution. All measurements were carried out at $20{ }^{\circ} \mathrm{C}$ and in 200 $\mathrm{mM}$ phosphate buffer. 


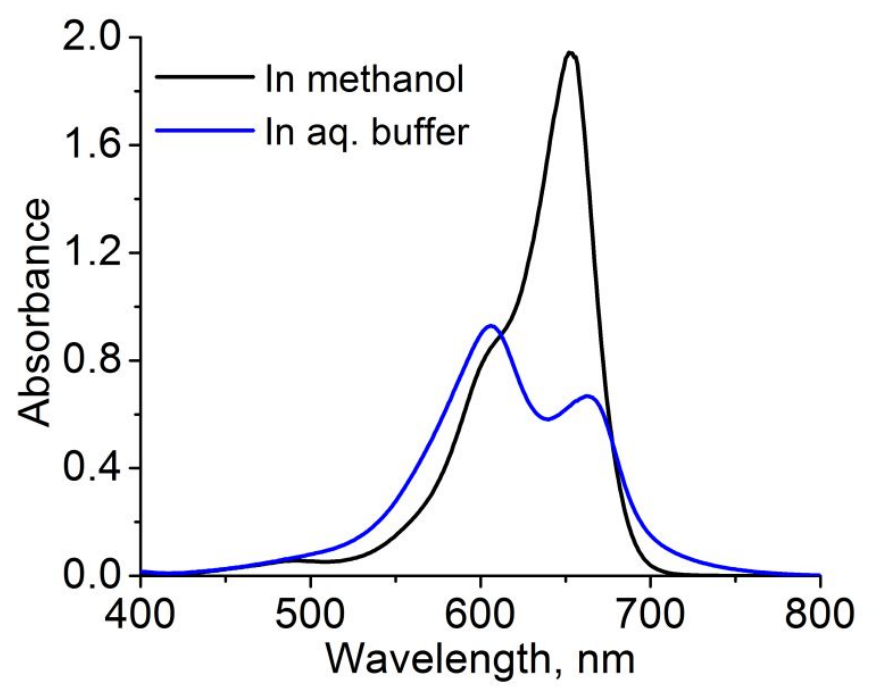

Figure S2. Absorption spectra of $0.25 \mathrm{mM}$ MB in methanol (black) and in 200 $\mathrm{mM}$ phosphate buffer at $\mathrm{pH} 7$ (blue).

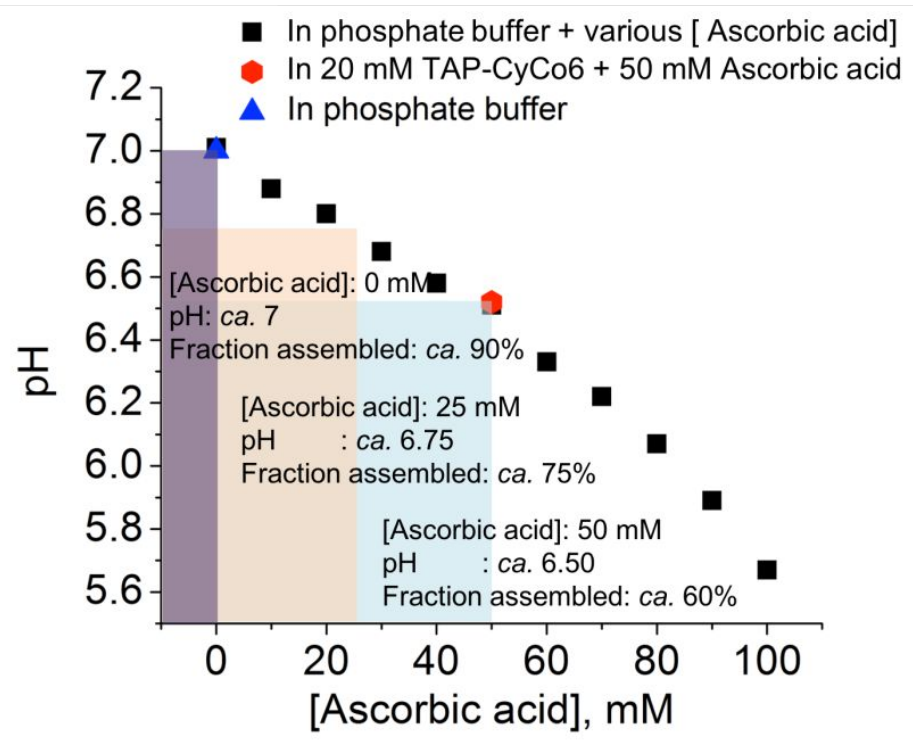

Figure S3. pH of the solutions of MB in buffer or TAP-CyCo6 assemblies with added ascorbic acid. Black squares show the changes in $\mathrm{pH}$ of $200 \mathrm{mM}$ phosphate buffer with various concentrations of ascorbic acid; the initial $\mathrm{pH}$ (ca. 7) of the solution is dropped in to $\mathrm{pH}$ ca. 6.75 with $50 \mathrm{mM}$ ascorbic acid and $\mathrm{pH}$ ca. 5.7 with $100 \mathrm{mM}$ ascorbic acid. Blue triangle shows the $\mathrm{pH}$ of a solution containing $0.25 \mathrm{mM}$ MB in phosphate buffer; addition MB did not change the $\mathrm{pH}$ of the buffer solution. The red hexagon shows the pH of $20 \mathrm{mM}$ TAP-CyCo6 and $50 \mathrm{mM}$ MB in phosphate buffer with $50 \mathrm{mM}$ ascorbic acid; $\mathrm{pH}$ of the final mixture is found to ca. 6.75 . 


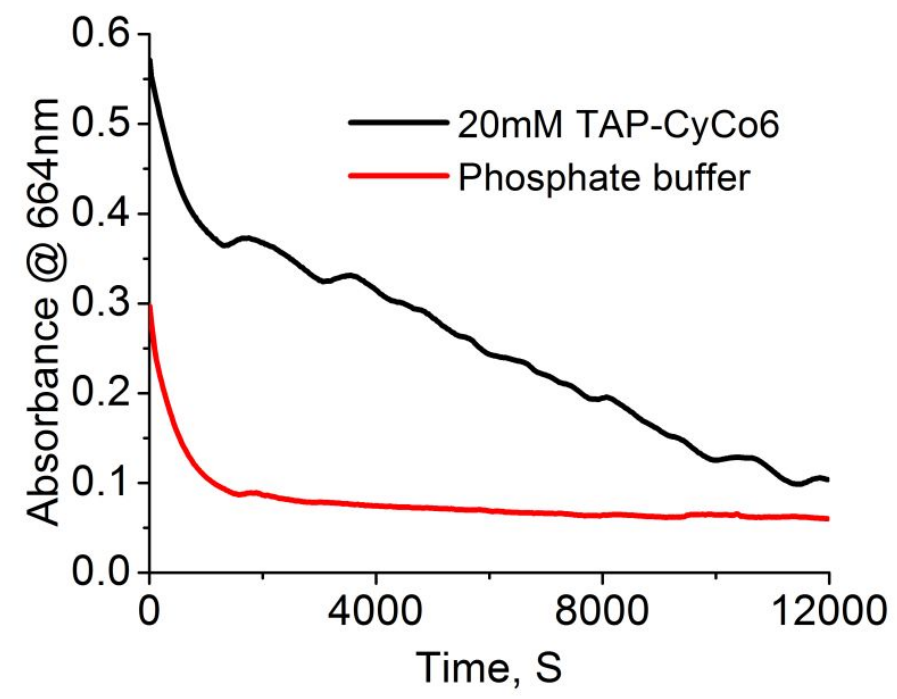

Figure S4. Absorption spectral changes of $0.25 \mathrm{mM}$ MB in $20 \mathrm{mM}$ TAP-CyCo6 solution (black) and phosphate buffer (red) with time. Much faster rate of reduction of MB is observed in phosphate buffer when compared to TAP-CyCo6 assembly. 